\title{
Changes of monoterpenes in stem of Chinese white pine (Pinus armandi) saplings following treatment with Methyl Jasmonate
}

\author{
Thanh Pham ${ }^{1,2}$, Hui Chen ${ }^{1,}$, Ranran Zhang ${ }^{1}$, Lulu Dai ${ }^{1}$ and \\ Thiquynhtrang $\mathrm{Vu}^{1}$
}

\begin{abstract}
Pham, T., Chen, H., Zhang, R., Dai, L., Vu, T. 2014. Changes of monoterpenes in stem of Chinese white pine (Pinus armandi) saplings following treatment with Methyl Jasmonate. - Forestry Studies | Metsanduslikud Uurimused 60, 69-81. ISSN 14069954. Journal homepage: http://mi.emu.ee/forestry.studies
\end{abstract}

\begin{abstract}
The Chinese white pine beetle (Dendroctonus armandi Tsai and Li) is the causal organism for the colossal death of the Chinese white pine (Pinus armandi Fr). We investigated the change of monoterpenes in the stem pholem and xylem in $P$. armandi saplings at 4 days, 8 days, and 30 days after treatment using treatment $(\mathrm{MeJa}+$ Tween-20 and Tween-20 as control) and untreated. GC-MS analysis found that the total monoterpene concentrations in the pholem and xylem in MeJa-treated saplings increased significantly compared with control or untreated saplings. Additionally, the proportions of $\beta$-pinene in the stem pholem, $\beta$-myrcene in the stem xylem, and limonene $+\beta$-phellandrene in both pholem and xylem of MeJa-treated saplings were increased significantly compared with control or untreated saplings. Based on our results, we suggest that by increasing the total concentration of monoterpene and the concentrations of $\beta$-myrcene, $\beta$-pinene and limonene $+\beta$-phellandrene maybe play an important defensive role against insect pests in $P$. armandi defense.
\end{abstract}

Keywords: Pinus armandi, methyl jasmonate, monoterpenes.

Authors's address: ${ }^{1}$ College of Forestry, Northwest A\&F University, Yangling, Shaanxi 712100, P.R., China; ${ }^{2}$ Hue University's College of Education, Hue, 47000, Vietnam; *e-mail: chenhui@nwsuaf.edu.cn

\section{Introduction}

Conifers contain a number of constitutive physical and chemical defences that help protect the tree from attack by pests (Lieutier et al., 2009; Eyles et al., 2010). The major chemical defence of conifers against insect, pests and pathogen contained terpenoids of oleoresin and phenolics (Franceschi et al., 2005). Oleoresin is primarily composed of monoterpenes (C10) and diterpene resin acids (C20) with trace amounts of sesquiterpenes (C15), which are synthesised in conifer species of the pinaceae family (Bohlmann \& Croteau, 1999; Phillips \& Croteau, 1999; Martin et al., 2002, 2003).
Terpenoids can kill herbivorous insects and pathogens or delay their development. In addition, terpenoids was describer both a physical and chemical defence system against stem-boring insects (Keeling \& Bohlmann, 2006a, 2006b).

The Chinese white pine (Pinus armandi Fr.) is the coniferous species native in China and it is grown in Qinling and Bashan mountains of China (Critchfield \& Little, 1966). It plays the main ecological role through protecting and resisting erosive soil, as well as providing tool for the socioeconomic development (Tang \& Chen, 1999). However, since 1954, $P$. armandi in the Qinling mountains have been damaged 
by the Chinese white pine beetle (Dendroctonus armandi Tsai and $\mathrm{Li}$ ) (Coleoptera: Curculionidae: Scolytinae), giving rise to colossal death of $P$. armandi trees (Tang \& Chen, 1999; Chen \& Tang, 2007; Chen et al., 2014; Hu et al., 2014). The study area, located on the southern slope of the middle Qinling Mountians (E 108 $21^{\prime}-108^{\circ} 39^{\prime}$, N 33ำ $18^{\prime}$ $33^{\circ} 28^{\prime}$ ), Shaanxi, China, is in the warm temperate climate zone and has a continental monsoon climate. The elevation is between 1450-2470 $\mathrm{m}$, the annual average temperature $8-10{ }^{\circ} \mathrm{C}$, the annual precipitation 900-1200 mm, and the frost-free period 170 days. There are various vegetation groups distributed in this region with altitudinal gradients, such as evergreen-deciduous mixed forest, deciduous broad leaved forest, temperate mixed forest, warm coniferous forest, temperate coniferous forest, and cold temperate coniferous forest.

In conifers, the application of Methyl Jasmonate (MeJa) causes anatomical and biochemical changes similar to those induced by wounding, insect assault, and pathogen invasion (Franceschi et al., 2002; Martin et al., 2002; Miller et al., 2005). Thus, we investigated constitutive and induced chemical responses of $P$. armandi saplings against a number of agents. This study was carried out to find out the possibility of MeJa to stimulate the invasion of bark beetles and Tween-20 was used as the control.

Previous reports described that while increasing monoterpenes in conifers using MeJa treatment it increase the resistance to insect pests. When apply MeJa to the plants, it increases the monoterpenes of Picea abies (Karst.) which is resistant against bark beetles of Pissodes strobi Peck., Ips typographus L. and bark beetle-associated Ceratocystis polonica (Siem.) C. Moreau (Martin et al., 2002; Erbilgin et al., 2006; Zeneli et al., 2006; Krokene et al., 2008; Zhao et al., 2010).

In addition to that, after applying MeJa, it increases the concentration of monoterpens in the Pinus species of $P$. sylvestris (L.), P. banksiana (Lamb.) and increase the resistance to bark beetle Hylobius abietis
(L.). (Hejari et al., 2005; Erbilgin \& Colgan, 2012). Thus, in this study we are only focused on monoterpenes in the stem in $P$. armandi saplings.

Conifers have evolved sophisticated constitutive and inducible defense mechanisms that reside in both bark and sapwood. Constitutive defenses include resin filled ducts in both bark and sapwood (Wu \& Hu, 1997; Krekling et al., 2004). Traumatic resin ducts in developing stem xylem and increased accumulation of oleoresin terpenoids in bark and wood tissues (Franceschi et al., 2002; Martin et al., 2002, 2003). Thus, we have examined the effect of MeJa on changes in monoterpenes compounds, and quantify the monoterpenes in the pholem and xylem of $P$. armandi saplings with the time sequence (Pham et al., 2014). Further, it helped to understand the role of host's defense mechanism which protecting the tree from pest attacks and to understand the role of different stem tissues against pests.

\section{Material and Methods}

\section{Plant material}

The P. armandi seeds from which the saplings were grown were collected from the Hoaditang Experimental Forest Farm, Qingling Forest Ecological Station, southern slope of the Qinling Mountains in middle Ningshan county, Shaanxi province, China (E $108^{\circ} 24^{\prime}-108^{\circ} 29^{\prime}$, N $33^{\circ} 18^{\prime}-33^{\circ} 28^{\prime}$ ). P. armandi saplings were raised in a nursery at the College of Forestry, Northwest A\&F University, P.R., China for 2 years under natural light and environmental conditions. The saplings were grown until they reached a height of 40 to $50 \mathrm{~cm}$. Thus, the saplings were moved to a greenhouse in constant conditions with a day/night temperature of $25^{\circ} \mathrm{C}$, a day/night humidity of $50 \%$ and photoperiod by high-pressure sodium lamps, where they were watered daily (100 mL for one plant) and fertilised (50 mL for one plant) weekly for 8 weeks. 
After the application of the experimental treatments, fertilisation was stopped to exclude any nutrient-defence interactions (Zhao et al., 2008).

\section{MeJa treatment}

The MeJa treatment was modified from Martin et al. (2003). Seedlings were placed in a ventilated fume hood, three saplings were treated and each plant was sprayed with 100 $\mathrm{mL}$ of $0.01 \%$ (v/v) MeJa (Sigma-Aldrich, St. Louis, $95 \%$ pure, w/w) dissolved in $0.1 \%$ Tween-20 solution. After 1 hour of treatment, excess MeJa solution was allowed to evaporate before plants were transferred to growth chambers. The control plants were sprayed with $100 \mathrm{~mL}$ of $0.1 \%$ Tween-20 dissolved water solution. The whole experiment included 2 elicitor treatment (MeJa + Tween-20 and Tween-20) and untreated (water) $\times 3$ time (4, 8 and 30 days) $\times 3$ replicated plants, and thus the total number of plants in study was 27.

\section{Tissue harvesting}

Stems were harvested at 4 days, 8 days and 30 days to extract monoterpenes. Tissue harvest was performed according to Miller et al. (2005). Each the time points harvested three saplings for each treatment. To harvest stem tissues, saplings were cut at the branches of the crown in defoliated and untreated and control saplings. The pholem and xylem of saplings were cut longitudinally with a razor blade and stored at $-80^{\circ} \mathrm{C}$.

\section{Analysis of monoterpenes}

The monoterpenes of extraction was modified according to the methods from Erbilgin \& Colgan (2012). All tissue was ground in liquid nitrogen using a mortar and pestle. One hundred milligrams of ground tissue was added to 500 microlitres of dichloromethane $\left(\mathrm{CH}_{2} \mathrm{Cl}_{2}\right)$ (Sigma-Aldrich, St Louis, MO, USA) with $0.1 \%$ tridecane (Sigma-Aldrich) as a surrogate standard in a $1.5 \mathrm{ml}$ microcentrifuge tube. The above mixture was vortexed for $30 \mathrm{~s}$, placed in an ultrasonic bath for $15 \mathrm{~min}$, and then centrifuged at $0{ }^{\circ} \mathrm{C}$ and $14 \mathrm{rpm}$ for $15 \mathrm{~min}$. The extract was pipetted into a gas chromatography vial and stored at $-80^{\circ} \mathrm{C}$. The mixture was then extracted for a second time using the same method. The second extract was added to the first and stored at $-80^{\circ} \mathrm{C}$ until chemical analysis.

Extracts $(1 \mu \mathrm{l})$ were analysed using a GCMS-QP2010 Ultra device (Shimadzu Corpotion, Kyoto, Japan) equipped with an RXI-5ms column $(0.25 \mu \mathrm{m} \times 0.25 \mu \mathrm{m} \times$ $30 \mathrm{~m})$, helium carrier gas flow at $1 \mathrm{~mL}$ $\min ^{-1}$, and a split ratio of 10:1 (for both the bark and wood). The temperature was set at $50{ }^{\circ} \mathrm{C}$ for $2 \mathrm{~min}$, was then increased to $160{ }^{\circ} \mathrm{C}$ by $5^{\circ} \mathrm{C} \mathrm{min}^{-1}$ and then to $250{ }^{\circ} \mathrm{C}$ by $15^{\circ} \mathrm{C} \min ^{-1}$ (15 min hold).

The identification of monoterpenes was based on a comparison of retention times and mass spectra with authentic standards or with mass spectra in the Wiley or National Institute of Standards and Technology libraries, NIST 08 mass spectral database library, http://webbook.nist.gov/ chemistry/, and previous report have been described monoterpenrs in conifer according from those in Martin et al. (2002), Zeneli et al. (2006) and Arrabal et al. (2012).

Terpene concentrations were calculated by integration of peak area and normalization against peak areas of tridecane standards. Mean terpenoid concentration in $\mathrm{mg} \cdot \mathrm{g}^{-1}$ dry weight were determined, and standard error were calculated.

\section{Statistical analysis}

Total monoterpene concentrations and their interactions in the phloem and xylem were tested using General Linear Model (GLM) with Tukey's test in SPSS 18.0 (IBM SPSS Statistics, Chicago, IL, USA). When the interaction was not significant, a oneway analysis of variance (ANOVA) has been used to examine the differences between the treated and the untreated saplings. Total monoterpene concentrations in the phloem and xylem were transformed for analysis. Total monoterpene concentra- 


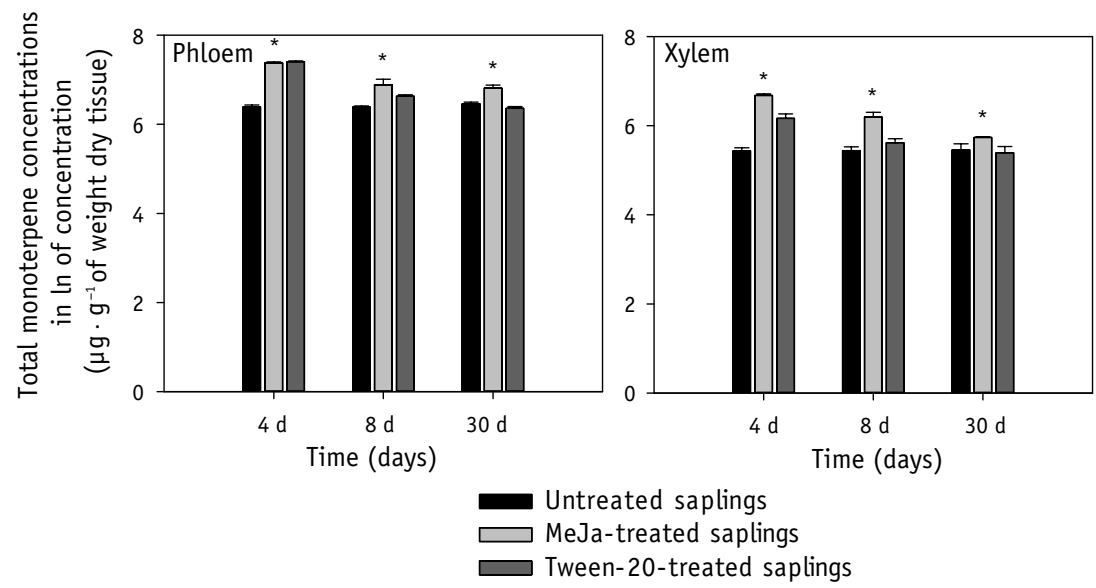

Figure 1. The total monoterpene concentrations $\left(\mu \mathrm{g} \cdot \mathrm{g}^{-1}\right.$ of dry weight tissue) in the phloem and xylem of the stem of Pinus armandi saplings differ among treatments at each time point. Data were transformed (In) for analysis. * Indicates that there was a significant difference $(p<0.05)$ among treatments using ANOVA at each time point. Each bar represents the mean total \pm standard error of three saplings.

tions in the phloem and xylem after treatment were tested using ANOVA to examine the differences between time points in individual treatments.

The monoterpene composition of all tissues was analysed by examining individual monoterpenes and as a proportion of total concentration. Individual monoterpenes (a-pinene, $\beta$-myrcene, $\beta$-pinene, 3 -carene, bornyl acetate, camphene, and limonene $+\beta$-phellandrene) were tested, as they represented more than $90 \%$ of the total monoterpene concentrations in the phloem and xylem (Supplementary Material and Data Deposit). We conducted GLM of the individual monoterpenes and their interaction in the phloem and xylem to examine the differences among treatments at each time point. When the interaction was not significant, a one-way analysis of variance (ANOVA) for individual monoterpenes were used. The individual monoterpenes in the phloem and xylem were analyzed without transformations of the data. ANOVA was carried out to calculate the differences of monoterpene among the time points in the individual treatments.
Finally, we also examined the proportional change in monoterpenes in the phloem and xylem relative to the corresponding in untreated saplings $(\Delta=$ [induced - untreated]/untreated). $T$-tests were used to compare the differences between the phloem and xylem for monoterpenes in the same treated saplings at all time points after treatment. Individual monoterpenes (a-pinene, $\beta$-pinene, bornyl acetate, and limonene $+\beta$-phellandrene) were assessed in terms of the proportional difference in concentrations from untreated saplings.

All statistics were calculated with SPSS 18.0. All plots were made with SigmaPlot 12.0 (Systat Software Inc, San Jose, CA, USA).

\section{Results}

Effect of MeJa and Tween-20 on monoterpenes in the stem xylem in $P$. armandi saplings

The total monoterpene concentrations in the xylem differed significantly among treatments at 4 days $(F=95.321, d f=2, p<$ 
Table 1. Tukey's tests showed significant differences results of comparisons of total monoterpenes in the phloem and xylem of the stem among treatments at each time point and among time points in individual treatments. UT = Untreated saplings, MJ = MeJa-treated saplings, TW = Tween-20-treated saplings. Lower-case letters in a row show results of significant differences between treatments and capital letters in a column show results of significant differences between the time points. The same letters within each column (capital letters) and each row (lower-case letters) indicates no statistically significant differences.

\begin{tabular}{|c|c|c|c|c|c|c|}
\hline \multirow{4}{*}{$\begin{array}{l}\text { Time points } \\
\text { (days) }\end{array}$} & \multicolumn{6}{|c|}{ Tissue / Terpenoids / Treatments } \\
\hline & \multicolumn{3}{|c|}{ Phloem } & \multicolumn{3}{|c|}{ Xylem } \\
\hline & \multicolumn{3}{|c|}{ Total monoterpenes } & \multicolumn{3}{|c|}{ Total monoterpenes } \\
\hline & UT & MJ & TW & UT & $\mathrm{MJ}$ & TW \\
\hline 4 & $\mathrm{bA}$ & $\mathrm{aA}$ & $\mathrm{aA}$ & $c A$ & $a B$ & $\mathrm{bA}$ \\
\hline 8 & $\mathrm{bA}$ & $\mathrm{aB}$ & $a b B$ & $b B$ & $a B$ & $a b B$ \\
\hline 30 & $a b A$ & $a B$ & $b c$ & $a B$ & $\mathrm{aA}$ & $\mathrm{aB}$ \\
\hline
\end{tabular}

$0.001)$ and 8 days $(F=8.114, d f=2, p=0.02)$ after treatments (Figure 1). A Tukey's test showed that the total monoterpene concentrations in the xylem were significantly higher only in MeJa-treated saplings than in both control saplings and untreated saplings at 4 days after treatment (Table 1). Comparisons of total monoterpene concentrations among time points after treatment in individual treatments showed that the total monoterpene concentrations in the xylem differed significantly among time points after treatment in both MeJa-treated saplings $(F=28.024, d f=2, p<0.001)$ and control $(F=30.176, d f=2, p<0.001)$, whereas the corresponding total concentrations did not differ significantly among time points after treatment in untreated saplings. A Tukey's test showed that the highest monoterpene concentrations in both MeJa-treated and control saplings occurred at 4 days after treatment (Table 1).

The proportions of a-pinene, $\beta$-pinene, $\beta$-myrcene, 3-carene, bornyl acetate, camphene and limonene $+\beta$-phellandrene relative total concentrations in the xylem were analysed to know the difference among treatment at time points after treatments (Appendix 1). The results showed that the proportions of a-pinene, $\beta$-myrcene, bor- nyl acetate and limonene $+\beta$-phellandrene were significantly different among treatments at various time points after treatments (Figure 2). A Tukey's test indicated that the proportion of $\beta$-myrcene and limonene $+\beta$-phellandrene was significantly higher in MeJa-treated saplings than in both control and untreated saplings at 30 and 4 days after treatment, whereas the proportion of bornyl acetate was significantly higher in MeJa-treated and untreated saplings than in untreated saplings at both 4 and 30 days after treatment (Table 2 ). In contrast, the proportion of a-pinene was significantly higher in control saplings than untreated saplings at 30 days after treatment (Table 2). For other individual monoterpenes, there was no difference among treatments or between treated and untreated saplings at any time point $(p>$ 0.05, results not shown).

In addition, the proportion of $\beta$-myrcene in the xylem differed significantly among time points after treatment in MeJa-treated saplings. A Tukey's test indicated that the highest proportions of $\beta$-myrcene in MeJatreated saplings occurred at 30 days after treatment. In addition, the proportion of limonene $+\beta$-phellandrene in the xylem differed significantly among time points 

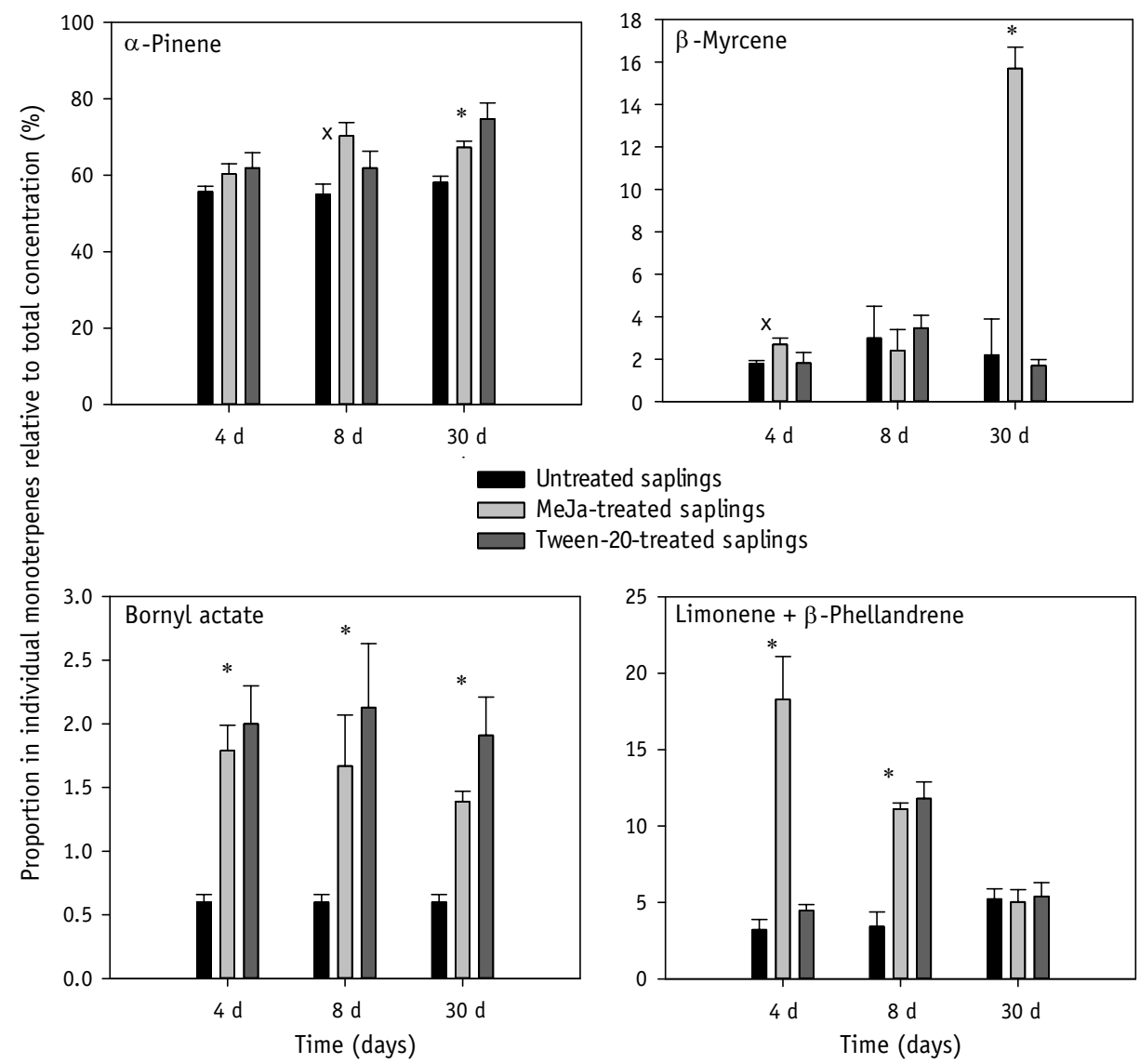

Figure 2. The proportional individual monoterpene (\%) in the xylem of the stem of Pinus armandi saplings relative to total concentrations differ among treatments at each time point. * Indicates that there was a significant difference $(p<0.05)$ between treatments using ANOVA at each time point and $\mathrm{x}$ indicates that there was a significant difference $(p<0.05)$ among MeJa-treated saplings and untreated saplings using ANOVA at each time point. Each bar represents the mean total \pm standard error of three saplings.

Table 2. Tukey's tests showed significant differences among comparisons of individual monoterpenes in the xylem of the stem among treatments at each time point and across different time points in individual treatments. UT = Untreated saplings, MJ = MeJA-treated saplings, TW = Tween-20-treated saplings. Lower-case letters in a row show results of significant differences between treatments and capital letters in a column show results of significant differences between the time points. The same letters within each column (capital letters) and each row (lower-case letters) indicates no statistically significant differences.

\begin{tabular}{|c|c|c|c|c|c|c|c|c|c|c|c|c|}
\hline \multirow{3}{*}{$\begin{array}{l}\text { Time } \\
\text { points } \\
\text { (days) }\end{array}$} & \multicolumn{12}{|c|}{ Terpenoids / Treatments } \\
\hline & \multicolumn{3}{|c|}{$\alpha$-Pinene } & \multicolumn{3}{|c|}{$\beta$-Myrcene } & \multicolumn{3}{|c|}{ Bornyl Acetate } & \multicolumn{3}{|c|}{ Limonene $+\beta$-Phellandrene } \\
\hline & UT & MJ & TW & UT & MJ & TW & UT & MJ & TW & UT & MJ & TW \\
\hline 4 & $\mathrm{aA}$ & $\mathrm{aA}$ & $\mathrm{aA}$ & $\mathrm{aA}$ & $\mathrm{aB}$ & $\mathrm{aA}$ & bA & $\mathrm{aA}$ & $\mathrm{aA}$ & bA & $\mathrm{aA}$ & $\mathrm{bB}$ \\
\hline 8 & $\mathrm{aA}$ & $\mathrm{aA}$ & $\mathrm{aA}$ & $\mathrm{aA}$ & $\mathrm{aB}$ & $\mathrm{aA}$ & bA & $a b A$ & $\mathrm{aA}$ & bA & $a A B$ & $a b A$ \\
\hline 30 & $\mathrm{aA}$ & $a b A$ & $\mathrm{aA}$ & $b A$ & $\mathrm{aA}$ & bA & bA & $\mathrm{aA}$ & $\mathrm{aA}$ & $\mathrm{aA}$ & $a B$ & $a b B$ \\
\hline
\end{tabular}


after treatment in both MeJa-treated and control saplings. A Tukey's test indicated that the highest proportions of limonene $+\beta$-phellandrene in MeJa-treated saplings occurred at 4 days after treatment, whereas the the corresponding proportion of limonene $+\beta$-phellandrene in control saplings was highest at 8 days after treatments (Table 2).

\section{Effect of MeJa and Tween-20 treatment on monoterpenes in stem phloem in $P$. armandi saplings}

In the phloem, total monoterpene concentrations differed significantly among treatments at 4 days $(F=393.972, d f=2, p<$ $0.001), 8$ days $(F=10.988, d f=2, p<0.001)$ and 30 days $(F=9.082, d f=2, p=0.015)$ after treatment (Figure 1). A Tukey's test indicated that the total monoterpene concentrations in the phloem were significantly higher in MeJa-treated saplings compared to the control saplings or untreated saplings at 8 and 30 days after treatment. In addition, the total monoterpene concentrations in the phloem were significantly different among time points after both MeJa and control treatment (Table 1).

The proportions of a-pinene, $\beta$-myrcene, $\beta$-pinene, bornyl acetate, camphene and limonene $+\beta$-phellandrene relative to concentrations in the phloem were analysed to ascertain the difference among treatments at different time points after treatments (Appendix 2). This result showed that the proportions of $\beta$-pinene, $\beta$-myrcene and limonene $+\beta$-phellandrene were significantly different among treatments at various time points (Figure 3). For other individual monoterpenes, there were no differences among treatments or between treated and untreated saplings at any time point ( $p>0.05$, results not shown). The proportions of $\beta$-pinene were significantly higher in MeJa-treated saplings than in both control and untreated saplings at 8 days after treatment, whereas the proportions of limonene $+\beta$-phellandrene was significantly higher in MeJa-treated saplings than both control and untreated saplings at 4 days after treatment (Table 3). In contrast, the proportion of $\beta$-myrcene was significantly higher in control saplings than in both MeJa-treated or untreated saplings at 4 days after treatment (Table 3), but higher only in MeJa-treated saplings compared to the untreated sapling at 8 days after treatment. Comparisons of these compounds among time points after treatment in individual treatments showed that the proportions of $\beta$-myrcene was higher at 30 days after treatment in MeJa-treated saplings, whereas the proportions of limonene $+\beta$-phellandrene was higher at 4 days after treatment in MeJa-treated saplings (Table 3).

\section{Differential effect MeJa and Tween-20} on monoterpenes between phloem and xylem in the stem in $P$. armandi saplings

An examination of the proportional change of the total monoterpene concentrations in the same treated relative to the corresponding in untreated saplings showed that MeJa-treated showed significant differences between the phloem and xylem at 4 days after treatment, with a greater increased significantly in the xylem than in the pholem (Figure 4, Table 4). The proportional change in individual monoterpenes (a-pinene, $\beta$-pinene, $\beta$-myrcene, bornyl acetate, and limonene $+\beta$-phellandrene) relative to corresponding in untreated saplings was also examined. The proportional changes in limonene $+\beta$-phellandrene differed significantly between the phloem and xylem (at 4 days and 8 days after treatment for MeJa-treated saplings and 8 days for control saplings), with greater increase in the xylem than in the pholem (Figure 4 , Table 4). For the proportional changes in $\beta$-pinene in MeJa-treated and control saplings did not exhibit significant differences over time between the phloem and xylem after treatment. In addition, other individual monoterperne in MeJa-treated saplings had significant differences between the phloem and xylem (at 4 days 

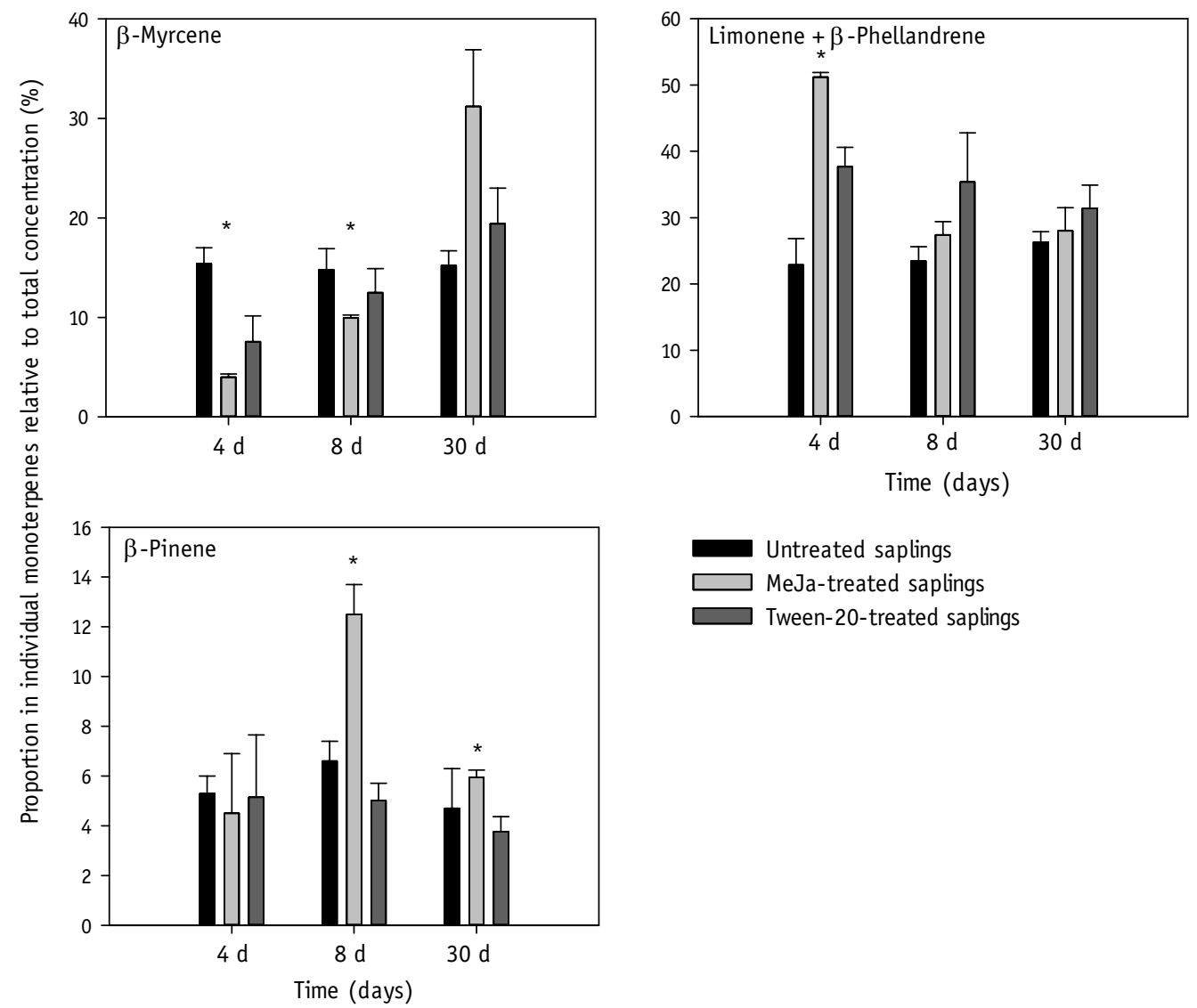

Figure 3. The proportional individual monoterpene (\%) in the phloem of the stem of Pinus armandi saplings relative to total concentrations differ among treatments at each time point. * Indicates that there was a significant difference $(p<0.05)$ between treatments using ANOVA at each time point $(p<0.05)$. Each bar represents the mean total \pm standard error of three saplings.

Table 3. Tukey's tests showed significant differences across comparisons of individual monoterpenes in the phloem of the stem among treatments at each time point and at different time points in individual treatments. UT = Untreated saplings, MJ = MeJa-treated saplings, TW = Tween-20-treated saplings. Lower-case letters in a row show results of significant differences between treatments and capital letters in a column show results of significant differences between the time points. The same letters within each column (capital letters) and each row (lower-case letters) indicates no statistically significant differences.

\begin{tabular}{cccccccccc}
\hline & \multicolumn{1}{c}{ Terpenoids / Treatments } \\
\cline { 2 - 9 } $\begin{array}{c}\text { Time points } \\
\text { (days) }\end{array}$ & \multicolumn{3}{c}{$\alpha$-Pinene } & \multicolumn{3}{c}{$\beta$-Pinene } & \multicolumn{3}{c}{$\begin{array}{c}\text { Limonene } \\
+\beta \text {-Phellandrene }\end{array}$} \\
\cline { 2 - 10 } & $\mathrm{UT}$ & $\mathrm{LG}$ & $\mathrm{MC}$ & $\mathrm{UT}$ & $\mathrm{LG}$ & $\mathrm{MC}$ & $\mathrm{UT}$ & $\mathrm{LG}$ & $\mathrm{MC}$ \\
\hline 4 & $\mathrm{aA}$ & $\mathrm{aB}$ & $\mathrm{aB}$ & $\mathrm{aA}$ & $\mathrm{aB}$ & $\mathrm{aAB}$ & $\mathrm{aA}$ & $\mathrm{aA}$ & $\mathrm{aA}$ \\
8 & $\mathrm{aA}$ & $\mathrm{bB}$ & $\mathrm{aA}$ & $\mathrm{aA}$ & $\mathrm{aAB}$ & $\mathrm{aA}$ & $\mathrm{aA}$ & $\mathrm{aA}$ & $\mathrm{aA}$ \\
30 & $\mathrm{aA}$ & $\mathrm{bA}$ & $\mathrm{aB}$ & $\mathrm{bA}$ & $\mathrm{aA}$ & $\mathrm{bB}$ & $\mathrm{bA}$ & $\mathrm{aA}$ & $\mathrm{abA}$ \\
\hline
\end{tabular}



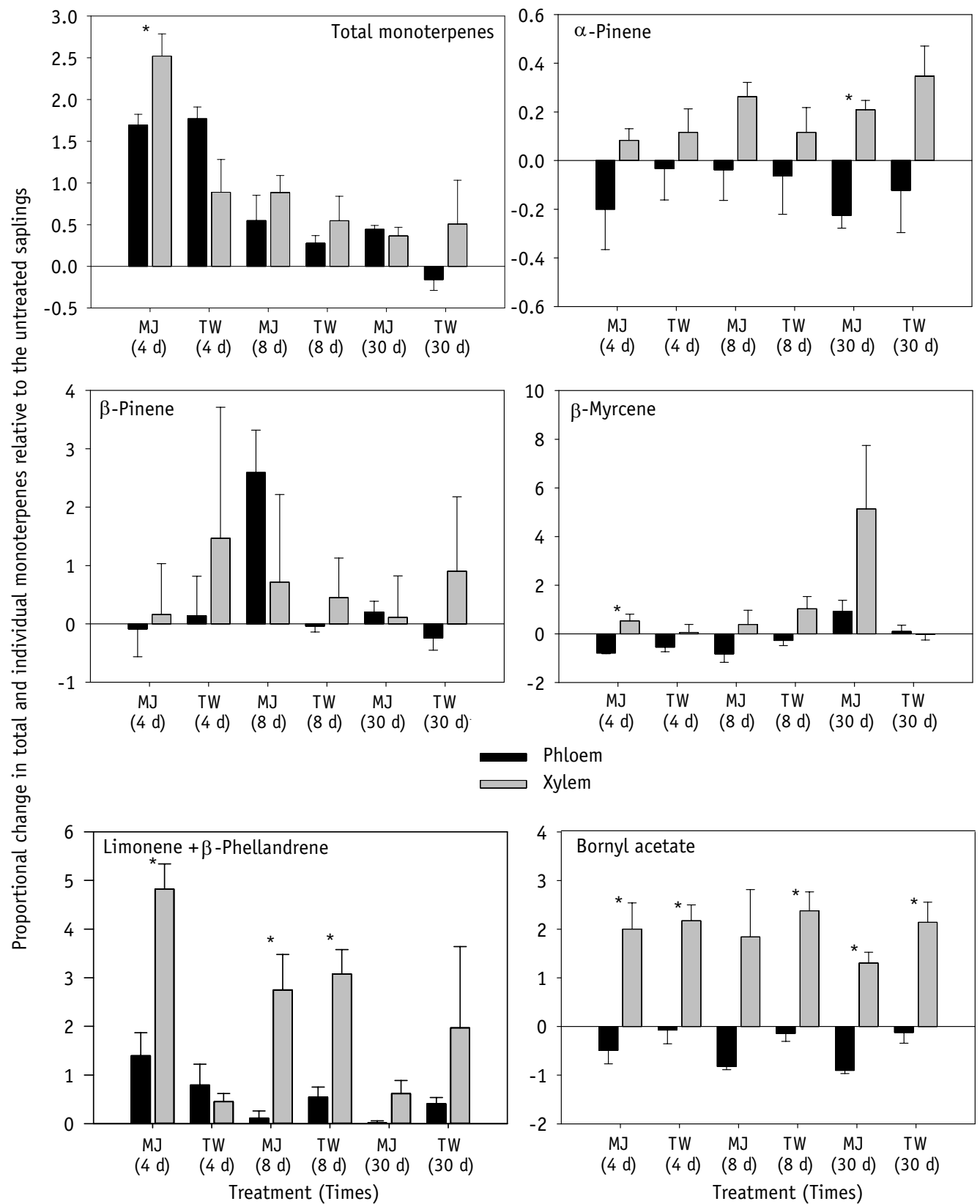

Figure 4. The change in total and individual monoterpenes between the phloem and xylem of the stem in treated saplings relative to the corresponding total and individual monoterpenes in untreated saplings at all time points after treatment. MJ = MeJA-treated saplings, TW = Tween-20-treated saplings. * Indicates that there was a significant difference $(p<0.05)$ between the phloem and xylem of the stem in the same treated saplings based on a Student $t$-test at the time points. Each bar represents the mean total \pm standard error of three saplings. 
Table 4. Comparison of total and individual monoterpenes between stem phloem and xylem in Pinus armandi saplings relative to corresponding monoterpenes the concentration in the untreated saplings at all time points after treatment. Bold-face numbers indicate a significant difference in a $t$-test between the stem bark and wood in the same treated over time $(p<0.05)$.

\begin{tabular}{|c|c|c|c|c|c|c|c|}
\hline \multirow{2}{*}{ Monoterpene } & \multirow{2}{*}{$\begin{array}{l}\text { Time } \\
\text { points }\end{array}$} & \multicolumn{3}{|c|}{$\begin{array}{l}\text { MeJa-treated saplings } \\
\text { bark vs. wood }\end{array}$} & \multicolumn{3}{|c|}{$\begin{array}{l}\text { Control saplings } \\
\text { bark vs. wood }\end{array}$} \\
\hline & & Diff. mean & $t$ & $p$ & Diff. mean & $t$ & $p$ \\
\hline \multirow{3}{*}{$\begin{array}{l}\text { Monoterpene } \\
\text { concentrations }\end{array}$} & 4 days & -0.827 & -2.809 & 0.048 & 0.881 & 2.106 & 0.103 \\
\hline & 8 days & -0.336 & -0.918 & 0.410 & -0.270 & 0.880 & 0.428 \\
\hline & 30 days & 0.080 & 0.707 & 0.519 & -0.668 & -1.236 & 0.284 \\
\hline \multirow{3}{*}{$\alpha$-Pinene } & 4 days & -0.284 & -1.646 & 0.175 & -0.149 & -0.926 & 0.470 \\
\hline & 8 days & -0.300 & -2.155 & 0.097 & -0.179 & -0.951 & 0.395 \\
\hline & 30 days & -0.433 & -6.635 & 0.003 & -0.468 & -2.915 & 0.093 \\
\hline \multirow{3}{*}{$\beta$-Pinene } & 4 days & -0.249 & -0.251 & 0.841 & -1.33 & -0.568 & 0.601 \\
\hline & 8 days & 1.876 & 1.127 & 0.323 & -0.487 & -0.710 & 0.517 \\
\hline & 30 days & 0.095 & 0.129 & 0.903 & -1.141 & -0.884 & 0.426 \\
\hline \multirow{3}{*}{$\beta$-Myrcene } & 4 days & -1.322 & -4.768 & 0.009 & -0.602 & -1.583 & 0.188 \\
\hline & 8 days & -1.216 & -1.807 & 0.145 & -1.304 & -2.387 & 0.075 \\
\hline & 30 days & -4.211 & -1.590 & 0.187 & 0.124 & 0.362 & 0.736 \\
\hline \multirow{3}{*}{ Bornyl acteate } & 4 days & -2.493 & -4.123 & 0.015 & -2.245 & -5.207 & 0.007 \\
\hline & 8 days & -2.662 & -2.726 & 0.053 & -2.254 & -5.992 & 0.004 \\
\hline & 30 days & -2.208 & -9.536 & $<0.001$ & -2.263 & -4.789 & 0.009 \\
\hline \multirow{3}{*}{$\begin{array}{l}\text { Limonene } \\
+\beta \text {-phellandrene }\end{array}$} & 4 days & -3.424 & -4.882 & 0.008 & 0.339 & 0.737 & 0.502 \\
\hline & 8 days & -2.633 & -3.528 & 0.024 & -2.257 & -4.626 & 0.01 \\
\hline & 30 days & -0.602 & -2.184 & 0.09 & -1.563 & -0.935 & 0.403 \\
\hline
\end{tabular}

for $\beta$-myrcene, 8 days for a-pinene and 4 days and 30 days for bornyl acetate after treatment). These compounds increased in the xylem compared with untreated saplings but decreased in the phloem. In the control saplings differed significantly only between the phloem and xylem for bornyl acetate at all time points after treatment, with increase in the xylem compared with untreated saplings but decreased in the phloem (Figure 4, Table 4).

\section{Discussion}

In this research, study the changes in monoterpenes compounds which plants used for chemical defence have been compared in the phloem and xylem in P. armandi saplings after treatment of MeJa. The data revealed that, the total monoterpene concentration in the phloem and xylem in P. armandi saplings has significantly increased after MeJa treatment compared with control or untreated saplings. Monoterpenes resistance to invasion of bark beetles in 
bark of host tree and repel or kill them (Raffa \& Berryman, 1983; Raffa \& Smalley, 1995). Thus, in this study, the increased total monoterpenes concentration represented a component of resistance to MeJa treatment, suggesting that it may play an important role against insect pests such as bark beetle in this host defence.

The relative amounts of a-pinene, $\beta$-pinene, $\beta$-phellandrene, 3-carene, camphene, bornyl acetate, limonene, and myrcene were found to increase in both the phloem and xylem tissue in $P$. abies trees after MeJa treatment than untreated trees (Martin et al., 2002). Also, myrcene concentration in $P$. banksiana juvenile was much higher after MeJa application than in the control treatment (Tween-20 treatment) (Erbilgin \& Colgan, 2012). Moreover, $\beta$-pinene and limonene in $P$. abies increased significantly after MeJa treatment (Zhao et al., 2010). In the present study, the proportions of $\alpha$-pinene, $\beta$-myrcene, bornyl acetate, and limonene $+\beta$-phellandrene in the $x y-$ lem had increased significantly after MeJa treatment than untreated saplings, but $\beta$-myrcene and limonene $+\beta$-phellandrene were significantly higher only in MeJatreated saplings than in control saplings. Whereas, the proportion of $\beta$-myrcene, $\beta$-pinene, and limonene $+\beta$-phellandrene in the phloem increased significant after MeJa treatment compared to the untreated saplings, but the proportion of $\beta$-pinene and limonene were only significantly higher in MeJa-treated saplings than in control saplings. The proportion of a-pinene and limonene made olfactory receptor neurons in $H$. abietis to respond strongly (Wibe et al., 1998). Through this study, it was suggested that, $\beta$-myrcene, $\beta$-pinene, and limonene $+\beta$-phellandrene play a critical role in monoterpene defence against insect pests. To prove the role of those monoterpenes in P. armandi defense, further experiments must be carried out to examine the specificity of MeJa for monterpenes defenses in this host. The monoterpenes must be analysed self-contained of other factors and the plants tested with insect pests such as bark beetle and pathogens.

MeJa treatment induced the formation of traumatic resin ducts in the developing xylem, enhanced resin flow and stimulated increased accumulation of monoterpenes, sesquiterpenes and diterpene resin acids (Zeneli et al., 2006). In our study, total and individual monoterpene concentrations (a-pinene, $\beta$-myrcene, bornyl acetate, and limonene $+\beta$-phellandrene) in MeJa-treated saplings were significantly higher in the xylem than in the pholem. Thus, we can suggest that the changes of monoterpenes have an aptitude to overcome insect pest invasion.

Acknowledments. We acknowledge the financial support of the National Natural Science Foundation of China (31170607, 31170567), the Program for Changjiang Scholars and the Innovative Research Team at the University of China (IRT1035).

\section{References}

Arrabal, C., Concepción García-Vallejo, M., Cadahia, E., Cortijo, M., Fernández de Simón, B. 2012. Characterization of two chemotypes of Pinus pinaster by their terpene and acid patterns in needles. - Plant systematics and Evolution, 298, 511-522.

Bohlmann, J., Croteau, R. 1999. Diversity and variability of terpenoid defenses in conifers, molecular genetics, biochemistry and evolution of the terpene synthase gene family in grand fir (Abies grandis). - Chadwick, D.J. Goode, J.A. (eds.). Insect Plant Interactions and Induced Plant Defense. West Sussex, John Wiley and Sons Ltd., UK. 253 pp.

Chen, H., Li, Z., Tang, M. 2010. Laboratory evaluation of flight activity of Dendroctonus armandi (Coleoptera: Curculionidaes Scolytinea). - Canadian Entomology, 142, 378-387.

Chen, H., Tang, M. 2007. Spatial and temporal dynamics of bark beetles in Chinese white pine in Qinling Mountains of Shaanxi Province, China. Environ, 5, 1124-1130.

Critchfield, W.B., Little, E.L. 1966. Geographic Distribution of the Pines of the World. Washington DC, Department of Agriculture, Forest Service, 11-12.

Erbilgin, N., Christiansen, E., Krokene, P., Zeneli, G., Gershenzonl, J. 2006. Exogenous application 
of methyl jasmonate elicits defences in Norway spruce (Picea abies) and reduces host colonization by the bark beetle Ips typographus. - Oecologia, 148, 426-436.

Erbilgin, N., Colgan, L.J. 2012. Differential effects of plant ontogeny and damage type on phloem and foliage monoterpenes in Jack pine (Pinus banksiana). - Tree Physiology, 32, 946-957.

Eyles, A., Bonello, P., Ganley, R., Mohammed, C. 2010. Induced resistance to pests and pathogens in trees. - New Phytologist, 185, 893-908.

Franceschi, V.R., Krekling, T., Christiansen, E. 2002. Application of methyl jasmonate on Picea abies (Pinaceae) stems induces defense-related responses in phloem and xylem. - American Journal of Botany, 89, 578-586.

Franceschi, V.R., Krokene, P., Christiansen, E., Krekling, T. 2005. Anatomical and chemical defences of conifer bark beetles and other pests. - New Phytologist, 167, 353-375.

Heijari, J., Nerg, A.M., Kainulainen, P., Viiri, H., Vuorinen, M., Holopainen, J.K. 2005. Application of methyl jasmonate reduces growth nut increases chemical defence and resistance against Hylobius abietis in Scots pine seedlings. - Entomologia Experimentalis et Applicata, 115, 117-124.

$\mathrm{Hu}$, X., Wang, C.Y., Wang, L., Zhang, R.R., Chen, H. 2014. Influence of temperature, $\mathrm{pH}$ and metal ions on guaiacol oxidation of purified laccase from Leptographium qinlingensis. - World Journal of Microbiology \& Biotechnology, 30, 1285-1290.

Keeling, C.I., Bohlmann, J. 2006a. Genes, enzymes and chemicals of terpenoid diversity in the constitutive and induced defence of conifers against insects and pathogens. - New Phytologist, 170, 657-675.

Keeling, C.I., Bohlmann, J. 2006b. Diterpene resin acids in conifers. - Phytochemistry, 67, 2415-2423.

Krekling, T., Franceschi. V.R., Krokene, P., Solheim, H. 2004. Differential anatomical response of Norway spruce stem tissues to sterile and fungus infected inoculations. - Trees, 18, 1-9.

Krokene, P., Nagy, N.E., Solheim, H. 2008. Methyl jasmonate and oxalic acid treatment of Norway spruce, anatomically based defense responses and increased resistance against fungal infection. Tree Physiology, 28, 29-35.

Lieutier, F., Yart, A., Salle, A. 2009. Stimulation of tree defenses by Ophiostomatoid fungi can explain attack success of bark beetles on conifers. Annals of Forest Science, 801,1-22.

Martin, D.M., Gershenzon, J., Bohlmann, J. 2003. Induction of volatile terpene biosynthesis and diurnal emission by methyl jasmonate in foliage of Norway spruce (Picea abies). - Plant Physiology, 132, 1586-1599.

Martin, D.M., Tholl, D., Gershenzon, J., Bohlmann, J. 2002. Methyl jasmonate induces traumatic resin ducts, terpenoid resin biosynthesis, and terpenoid accumulation in developing xylem of
Norway spruce stems. - Plant Physiology, 129, 1003-1018.

Miller, B., Madilao, L.L., Ralph, S., Bohlmann, J. 2005. Insect-induced conifer defense, white pine weevil and methyl jasmonate induce traumatic resinosis, de novo formed volatile emissions, and accumulation of terpenoid synthase and octadecanoid pathway transcripts in Sitka spruce. Plant Physiology, 137, 369-382.

Pham, T., Chen, H., Yu, J.M., Dai, L.L., Zhang, R.R., Thi, Q.T.V. 2014. The differential effects of the blue-stain fungus Leptographium qinlingensis on monoterpenes and sesquiterpenes in the stem of Chinese white pine (Pinus armandi) saplings. Forests, 5, 2730-2749.

Phillips, M.A., Croteau, R. 1999. Resin based defenses in conifers. - Trends in Plant Science, 4, 184-190.

Raffa, K.F., Berryman., A.A. 1983. The role of host plant resistance in the colonization behaviour and ecology of bark beetles (Coleoptera, Scolytidae). Ecological Monographs, 53, 27.

Raffa, K.F., Smalley, E.B. 1995. Interaction of preattack and induced monoterpene concentrations in host conifer defense against bark beetle-fungal complexes. - Oecologia, 102, 285-295.

Tang, M., Chen, H. 1999. Effect of symbiotic fungi of Dendroctonus armandi on host trees. - Scientia Silvae Sinicae, 35, 63-66.

Wibe, A., Borg-Karlson, A.K., Persson, M., Norin, T., Mustaparta, H. 1998. Enantiomeric composition of monoterpenes hydrocarbons in some conifers and receptor neuron discrimination of a-pinene and limonene enantiomers in the pine weevil. Journal of Chemical Ecology, 24, 273-287.

$\mathrm{Wu}, \mathrm{H} ., \mathrm{Hu}, \mathrm{Z}$. 1997. Comparative anatomy of resin ducts of the Pinaceae. - Trees, 11, 135-143.

Zeneli, G., Krokene, P., Christiansen, E., Krekling, T., Gershenzon, J. 2006. Methyl jasmonate treatment of mature Norway spruce (Picea abies) trees increases the accumulation of terpenoid resin components and protects against infection by Ceratocystis polonica, a bark beetle-associated fungus. - Tree Physiology, 26, 977-988.

Zhao, W., Chen, S.P., Lin, G.H. 2008. Compensatory growth responses to clipping defoliation in Leymus chinensis (Poaceae) under nutrient addition and water deficiency conditions. - Plant Ecology, 196, 85-99.

Zhao, T., Krokene, P., Björklund, N., Långström, B., Solheim, H., Christiansen, E., Borg-Karlson, A.K. 2010. The influence of Ceratocystis polonica inoculation and methyl jasmonate application on terpene chemistry of Norway spruce, Picea abies. - Phytochemistry, 71, 1332-1341. 


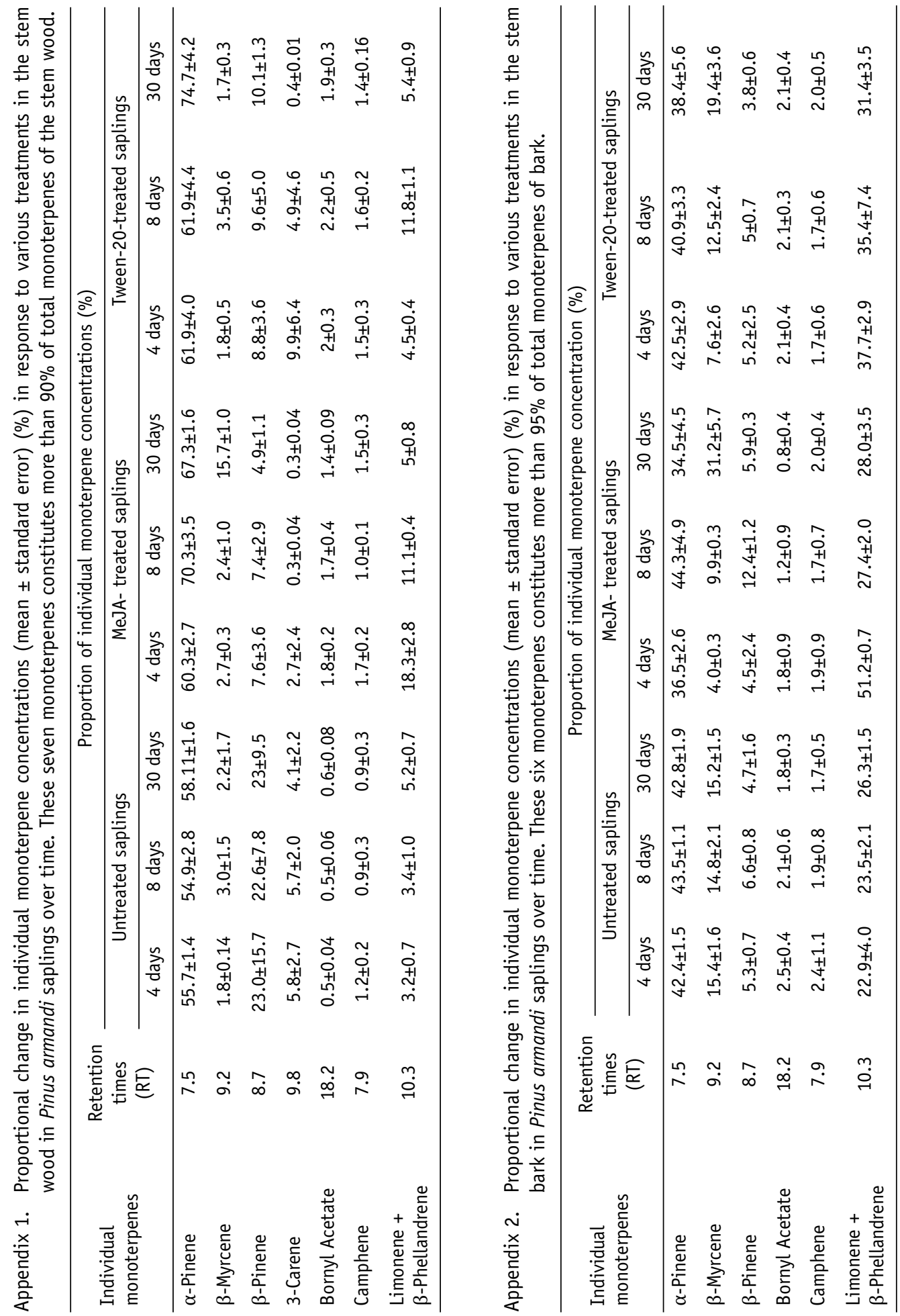

